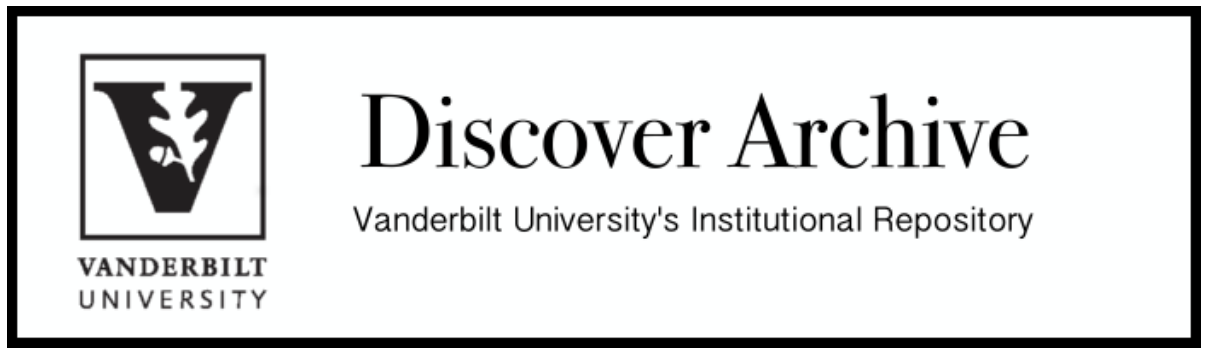

This work was originally published as: W. Kip Viscusi, Owen R. Phillips and Stephan Kroll, Risky Investment Decisions: How Are Individuals Influenced by Their Groups? - 43 Journal of Risk and Uncertainty 81 (2011). 
Risky Investment Decisions: How Are Individuals Influenced by Their Groups?*

by

\author{
W. Kip Viscusi \\ Vanderbilt University Law School \\ 13121 st Avenue South \\ Nashville, TN 37203-1181 \\ E-mail: kip.viscusi@ vanderbilt.edu \\ Phone: 615-343-7715 \\ Owen R. Phillips \\ Department of Economics \& Finance \\ University of Wyoming \\ Laramie, WY 82071-3985 \\ E-mail: owenphil@uwyo.edu \\ Phone: 307-766-2195 \\ Stephan Kroll \\ Department of Agricultural and Resource Economics \\ Colorado State University \\ Fort Collins, CO 80523-1172 \\ E-mail: stephan.kroll@ colostate.edu \\ Phone: 970-491-0887
}

July 11, 2011

*Research support from the Paul Lowham endowment is gratefully acknowledged. Any opinions, findings, conclusions, or recommendations expressed in this paper are those of the authors and do not necessarily reflect the views of the funding source. Jinghui Lim provided excellent research assistance. 


\title{
Risky Investment Decisions: How Are Individuals Influenced by Their Groups?
}

\author{
Abstract \\ We investigate the effect of group versus individual decision-making in the context of \\ risky investment decisions in which all subjects are fully informed of the probabilities and \\ payoffs. Although there is full information, the lottery choices pose cognitive challenges so that \\ people may not be sure of their expected utility-maximizing choice. Making such decisions in a \\ group context provides real-time information in which group members can observe others' \\ choices and revise their own decisions. Our experimental results show that simply observing \\ what others in the group do has a significant impact on behavior. Coupling real-time information \\ with group decisions based on the median value, i.e., majority rule, makes the median investment \\ choice focal, leading people with low values to increase investments and those with high values \\ to decrease investments. Group decisions based on the minimum investment amount produce \\ more asymmetric effects.
}

Key Words: real-time information, group decisions, experiments, herding JEL Classification: D03, D80, D70 
Risky decisions typically do not involve isolated choices among abstract lotteries.

Rather, there is often the opportunity to make an investment that affects the lottery structure. This additional element of choice increases the cognitive challenges posed by the risky decision, making it more difficult to ascertain the optimal choice. This article examines these individual decisions when made in a group context. Unlike existing treatments of herding effects, there is full information about probabilities and payoffs. The remaining uncertainty is with respect to individual preferences in the face of a complex task. Observing decisions by others in a group can potentially provide guidance with respect to the optimal choice. This article utilizes a series of experiments to explore this phenomenon.

Decisions that involve risk and require up-front investments often are made in a group environment. Examples abound. Families make down payments and finance improvements on their residence; they decide how much to spend and where to send children for their education; they save for retirement. Non-profit and for-profit boards approve major employment contracts, undertake new capital projects, and acquire other organizations or companies. Potentially large numbers of people vote on regulating business activity and funding community development. And in the context of our experimental design, groups consider whether to engage in litigation, where the cost of litigation is paid before the outcome is known. In general, risky financial decisions are arguably more prevalent in group environments than when individuals make decisions in isolation.

While the difference in decision-making behavior between groups and individuals has recently been the subject of much academic research, relatively little is known about group behavior in which there is an investment component to the risky decision. Individuals may act differently because of the separate and related effects of (1) being embedded in a group and (2) 
the group decision rule. Most theoretical and empirical models of risky decision-making assume that the decision-making group acts as a rational economic agent, without taking group informational dynamics and decision-making rules into account.

This article seeks to fill this void by presenting experimental evidence that illuminates how a group environment affects risky decisions. Individual investment decisions that affect the lottery structure are compared to those made in three different group environments in which the group faces the same range of risky investments as the individual. In each group context, participants have real-time information (RTI) that enables them to observe the desired investment amounts of others, and they can revise their investment recommendations based on these observations. Both RTI alone and the group decision rule-deciding how much to invest either based on the median value (as in majority rule) or the minimum value (as in unanimous rule) — may influence individual choices. The experimental design allows us to distinguish the separate effects of simply observing what others want to do and the group decision rule, track how people change, and test for significance.

Our experiment involves the choice of an investment amount, where higher investment levels at first increase the chance of obtaining a higher payoff, but after a point greater investment levels reduce the net expected payoff. To operationalize the investment decision in both an individual and group setting, we construct a decision context that makes people contemplate filing a lawsuit. In our scenarios, up-front investments must be made to earn an uncertain return.

Investing more in the lawsuit increases the probability of winning the case, but the expected payoff net of litigation costs eventually declines as the investment increases. Although subjects in our experiments are presented with this concrete decision problem, its general form is 
one that has a concave expected payoff schedule. Hence in terms of expected returns, too much can be invested to achieve a desired outcome. The temptation to throw money at an endeavor can easily be extended to other situations where emotions run high because of a strong desire to prevail, for example in paying for a child's rearing and education, or providing for the health care of a loved one. ${ }^{1}$

In the group settings, RTI allows every individual to instantly observe the amounts recommended by other members of the group; people can change their commitment to the endeavor as they see how others are committing. In two of the three group situations there is a common group decision based on either the median value or the minimum value that eventually determines an identical payoff for each member of the group. Because two treatment effects essentially take place in these group sessions, one being the decision rule and the other being able to observe what all group members want to invest in real time, we isolate the effect of RTI based on an RTI-only treatment, in which individuals are in a group that is strictly informational; they can observe what others do, but their payoffs depend only on their own decision.

A priori one would not expect there to be strongly different effects on an individual's behavior from these group contexts, particularly for the RTI case in which the individual's own investment determines the individual's payoff. All experimental participants have full information regarding probabilities and payoffs, and they can presumably make decisions based on their own willingness to bear risk. Thus, providing information on other people's decisions should have no effect if the individual's payoff is governed solely by one's individual choice. However, risky decisions pose well-known difficulties for individual decision-making. If individuals have noisy preferences and are uncertain about whether they have made their

\footnotetext{
${ }^{1}$ We create this type of choice environment as one with high potential for individual and/or group decisions to stray from a focus on marginal benefits and costs. For different reasons as described below, individual and group decisions can be very different in this setting.
} 
expected utility-maximizing choice, observing others' choices may provide information on possible errors in their private decision.

The experimental results show a strong influence of the group context. Being able to observe the decisions made by others influences subjects' choices irrespective of whether the lottery payoffs are based on the individual's investment decision, the majority group decision, or a unanimous group decision. In all these group contexts, subjects should select their personal utility-maximizing choice. Nevertheless, there is both an influence of others' preferences as well as the group decision rule. There are important framing effects on investment choices based on the group decision in conjunction with group members' choices.

Section 1 reviews the pertinent literature, much of which deals with herding effects. Unlike previous treatments of group decisions in which risky choices are influenced by others' behavior, our experimental subjects have full information about all probabilities and payoffs. Section 2 summarizes the experimental design, which consists of multiple components that make it possible to distinguish the informational impact of being in a group environment as well as the framing effects of the group decision rule. Section 3 presents our experimental hypotheses, several of which pertain to whether the group environment should lead to decisions that are more risky or less risky than when decisions are made in isolation. After providing an overall summary of the results in Section 4, Section 5 presents a detailed statistical analysis of the determinants of the levels of individual investment decisions, whether decisions made in a group context are more or less risky than decisions made in isolation, and the effect of the group decision rule. Section 6 concludes. 


\section{Comparison with Related Literature}

Our analysis of decisions in both individual and group contexts intersects with several related literatures. It is instructive to briefly review these intersections, as doing so helps in formulating the experimental hypotheses and in highlighting the distinctive nature of our study.

Because of the information exchanged in group contexts, choices made in a group environment may be different than those made by an individual not exposed to the choices of other people. Models of group polarization, such as Glaeser and Sunstein (2009), recognize herding effects or information cascades generated by observing others' choices, as this information may alter the assessed probabilities and consequently affect decisions in the group environment. ${ }^{2}$ The distinctive aspect of our work is that unlike all such previous studies, people in our study always have full information about all probabilities and payoffs. ${ }^{3}$ We find that participants alter their choices even though there is no uncertainty regarding the probabilities or the lottery payoffs; all participants have full information.

Unlike the findings in the existing literature, there is no rational basis for such an effect. What we suggest is that the complexity of making investment decisions that alter the lottery structure makes people unsure of their optimal investment account. Observing decisions made by others can potentially be of assistance.

\footnotetext{
${ }^{2}$ The information cascades analyzed by Bikhchandani, Hirshleifer, and Welch $(1992,1998)$ and the herding effects analyzed by Banerjee (1992) are defined similarly. In each case, individuals find it optimal to follow the actions of others rather than relying on their private information. Anderson and Holt (1997) present experimental evidence on these effects, while Daughety and Reinganum (1999) examine herding effects for judicial decisions. Rook (2006) provides a general review.

${ }^{3}$ To the extent that there is learning, it is with respect to others' decisions and one's own preferences. For our RTI environments, we suggest that behavioral changes are attributable to noisy individual preferences coupled with information about welfare-maximizing choices provided by RTI. Note the difference between our paper and research on the "wisdom of crowds." Here there is no right or wrong answer, and uncertainty exists only with regard to preferences and to the optimal strategy, while the wisdom of crowds refers to the (mathematical) fact that groups on the aggregate often come up with better answers to factual questions than individuals. In a recent paper, Lorenz et al. (2011) found experimental evidence that social influence can counteract the wisdom of crowds effect and can lead a group to wrong answers.
} 
If people observe risky decisions made by others in the group, will there be systematic effects on the riskiness of decisions? Will people become more risk-taking or less risk-taking after observing others' behavior? Changes in the riskiness of choices in the direction of taking greater risk are known as a risky shift; risk shifts associated with less risk are known as conservative shifts or cautious shifts. ${ }^{4}$ Most studies have found evidence of a risky shift. ${ }^{5}$ Shupp and Williams (2008) observe in a study on lottery valuation decisions that the difference in risk preferences between groups and individuals depends at least partly on the stakes: the average group is more risk-averse than the average individual in high-risk situations, while this is reversed for low-risk situations.

Our study differs from this literature in that for the experimental treatment that couples RTI with individual choice, there is no actual group interaction or group decision rule, only an exchange of information on choices. We compare the pure RTI results for individual decisions to the decisions individuals make when there is a group decision rule in order to analyze the nature of the risky shift across our different experimental treatments. In contrast to Shupp and Williams (2008), we do not allow for any form of communication even in treatments with groupdecision rules.

Our experimental design includes a component in which subjects make individual choices in a group context subject to a group decision rule that specifies either majority rule or unanimity. Whether the group decision rule affects investment decisions provides an additional perspective on whether there is an effect of influences other than those dictated by rational

\footnotetext{
${ }^{4}$ For analyses of risky shift and cautious shift (also called conservative shift) behavior, see Wallach, Kogan, and Bem (1962), Brown (1986), and Aronson, Wilson, and Akert (2005). Analogous group polarization effects have been found for mock jury behavior in Schkade, Sunstein, and Kahneman (2000).

${ }^{5}$ Ambrus, Greiner, and Pathak (2009) conduct experimental tests demonstrating that evidence of risky shifts in mean group decisions may provide a misleading perspective on the shifts in individual decisions. Their analysis of experimental lottery choices did not indicate any risky shift for individuals relative to the median.
} 
utility-maximizing choice. In particular, are there influential framing effects of the group decisions rule?

For RTI group contexts in which the investment amount is guided by the median or minimum decision rule, one would not expect the group context alone to alter individual choices. When preferences are single-peaked, basing group decisions on the median value is equivalent to the results with simple majority rule. When unanimity is required, the lowest individual investment in the group guides the group decision. Thus, our case in which the lowest investment amount determines the outcome is analogous to the unanimous choice case though our experiment does not require agreement by the entire group. The person with the lowest investment amount in the minimum value treatment has no incentive to raise that amount, and the subjects with the higher investment amounts have no incentive to lower their amounts in this group setting. ${ }^{6}$

When the group RTI environment is coupled with a group decision rule, we find framing effects and group norms at work even when group members interact in a relatively sterile environment that allows them to only register their investment "votes" on a computer screen.

Median investor and minimum investor rules not only define the payoff structure of the experiment but also have a framing effect in highlighting the pivotal values in the group context. Framing effects are well established in the psychology literature, but the major task always has been to predict ex ante how the frame will affect the decisions. ${ }^{7}$ The median and minimum value rules have well-defined, predictable focal points that are described in the experiments as being the instrumental value that will govern group decisions. By comparing the amounts spent as

\footnotetext{
${ }^{6}$ While one might not expect the group decision rule to alter individual choices, in an experiment with a very different structure than ours, Guarnaschelli, McKelvey, and Palfrey (2000) found experimental evidence of strategic, insincere behavior with both majority rule and a unanimity group decision rule.

${ }^{7}$ Fischhoff (1983) discusses the importance of decision frames and the difficulties that arise in predicting the effect of the frames ex ante rather than offering ex post rationalizations of framing effects that take advantage of hindsight.
} 
individuals alone and as individuals in a group, it is possible to quantify the effect of RTI and the framing and social norm effects of the group contexts on investments. ${ }^{8}$

The group investment decision is made by the subjects revealing how much they are willing to invest, rather than for example simply asking members for a vote on whether to invest a specific amount or not. These features of the experiment create a rich data set on how people and groups make decisions in a context that has risk, and for which net gains are concave. The findings provide evidence of a strong influence of RTI both when choices are governed by a group decision rule as well as when individuals make their own decision after being exposed to RTI from other members of the group.

\section{Experimental Design}

The experimental design compares an individual's investment decision with a group of six people facing the same decision. Each treatment consists of four parts - two lotteries (Part I and Part II), one individual investment decision (Part III), and one group investment decision (Part IV). These parts are sequenced differently in experimental sessions. The Part I and II lotteries were always stages 1 and 2 of an experimental session and were identical across all treatments.

To develop a risk aversion variable to be used as a control variable in the analysis of the risky investment decisions, in Part I of the experiment subjects considered the Holt and Laury (2002) lottery choices used to measure an individual's risk aversion. As described in Appendix A, subjects exhibited a moderate degree of risk aversion with a coefficient of relative risk

\footnotetext{
${ }^{8}$ The potential influence on group contexts as well as the salience of the group environment has been examined in experimental studies by Blinder and Morgan (2005), Cooper and Kagel (2005), Goette, Huffman, and Meier (2006), Charness, Rigotti, and Rustichini (2007), Tan and Bolle (2007), Sutter (2007, 2009) and Hargreaves-Heap and Zizzo (2009). Reviews of the related psychology literature appear in Brown (1986), Kerr, MacCoun, and Kramer (1996), and Aronson, Wilson, and Akert (2005).
} 
aversion of 0.21 . Only $17 \%$ of the subjects failed to express consistent lottery choices, and subsequent empirical analysis controls for this behavior. Appendix B describes the results of Part II of the experiment, which acquainted subjects with a lottery structure in which the expected payoff level rises then falls as the investment amount increases.

Part III, the individual investment decision, was also identical across all treatments, but in three treatments this part was conducted in stage 3 before the group decisions, which we refer to as original order, while in the other three treatments it was in stage 4 after the group decisions, which we refer to as reversed order. Finally, as we explain in more detail below, there were three variations of Part IV, the group investment decision. Table 1 provides an overview of the order of all parts in all six treatments. The treatments are different based on the order of the parts and the group environment in Part IV.

We recruited 144 subjects from college undergraduate and graduate classes. Each treatment consisted of two sessions with groups of 12, which were later divided into groups of six for the group treatments. Subjects reported to a computer lab, where each person was seated at a terminal. The experiment was programmed and conducted with the software z-Tree (Fischbacher 2007). At the beginning of each stage of the experiment, instructions were read aloud as subjects followed along on their written copies. Instructions to a subsequent stage of the experiment were not given to subjects until they had completed all of their choices in the current stage of the experiment. Sessions ran for about forty-five minutes from start to finish, when subjects were paid in cash. Average earnings were about $\$ 18.00$.

\subsection{Individual Investments}


To implement the lottery decision and establish the context for the subsequent group decision, Part III of the experiment gives subjects a hypothetical product liability case in which they must make a decision on going forward as a plaintiff. ${ }^{9}$ The instructions to subjects begin with the following case scenario.

Imagine a defective product has led to a serious injury to a member of your family. A product safety expert has reviewed the accident and concluded that the company was negligent in the manufacture of the product. Your attorney believes that you have a strong case to recoup damages from the manufacturer for the medical costs and pain and suffering associated with the accident.

The product manufacturer is a small firm that does not have a good safety record. The company has no insurance but relies instead on a policy of vigorously fighting any lawsuits against it. Your attorney advises you that the better you fund your potential case against the company the greater your chances of winning the case. However, the more you spend, the more the defendant spends, reducing the funds the company will have available to pay your claim. As a result, the amount of money you receive from winning the case falls as you spend more. If you lose the case you only have your original budget minus your payments.

Individuals in Part III of the experiment and groups of six in Part IV of the experiment are given a budget of $\$ 5.00$ to invest in this potential lawsuit. They must choose how much to invest and can choose to not file a complaint. The instructions present decision-makers with a sample table of what they can expect when they go forward with the case. The payoff structure is reported in Table 2, where the subjects were not informed of the expected lottery values that appear in parentheses. Outcome A is winning the case and Outcome B is losing the case. Since the decision variable is continuous, but the table shows only nine discrete choices, subjects are told that the table should be thought of "as nine example payments and possible outcomes."

In addition to providing the information in Table 2, subjects are informed that the probability of Outcome A is $(0.2 \mathrm{x}$ payment $)$ and the probability of Outcome B is (1- probability

\footnotetext{
${ }^{9}$ In another study with risky choices — which are presented either in abstract terms or as "investments"-Eckel and Grossman (2008a) found "little evidence that the framing of the gamble choice affects subjects' choices overall" (p.7).
} 
of Outcome A). The net amount paid if Outcome A results is \$15-2 x (\$ payment) and the net amount paid if Outcome B results is $\$ 5$ - (\$ payment). Table 2 adjusts in fifty cent increments, but subjects were reminded that they could choose any dollar and cents amount from $\$ 0.00$ to \$4.99. The expected values of the outcomes are shown in parentheses in the far right column for each entry. These values were not given to subjects in the experiment. Notice that the expected value function is concave. It starts at $\$ 5.00$, rises to a maximum of $\$ 6.25$, and then falls to $\$ 5.45$.

\subsection{Group Decisions}

Part IV, which is conducted in stage 3 or stage 4 of the experiment, is the "group" decision. In all of the experimental sessions there were twelve subjects divided anonymously into two groups of six, half of whom considered individual and group decisions in the original (Original) order and half considered group and individual choices in the reversed (Reversed) order. We will refer to the case in which the median decision determines the group investment decisions as majority rule and the minimum investment determines the group investment decision as unanimous rule. Dollars are votes that not only determine the relative standings of subjects but also are a measure of intensity of preferences. These dollar votes do not necessarily describe "willingness to pay" because of the nonlinearity of payoffs and the voting rule.

The group contexts consist of majority (Majority) rule (either Original-Majority or ReversedMajority), unanimous (Unanimous) rule (either Original-Unanimous or Reversed-Unanimous), and individual choice in a group of six with RTI so that they could observe (Observe) how the others were investing (Original-Observe or Reversed-Observe). In the latter RTI treatments without a group decision rule, subjects were told that they could observe the investment choices of the other five members of the group, but otherwise there was no interaction between members. 
Individuals in all group settings had a two-minute period in which to observe and revise their investment decisions as many times as they wished. ${ }^{10}$ Subjects were told that in majority rule the fourth-highest amount determined what the group pays. In unanimous rule the smallest amount determined the amount paid to undertake the lawsuit. This is the most that all six subjects will pay to go forward. Alternatively, it could be viewed as the marginal amount required for one individual to not go along with the group investment in the lawsuit.

\section{Hypotheses}

The choice situations in both the individual and group contexts involve investment decisions that affect the probabilities of a lottery outcome. Let $\mathrm{w}$ be the individual's initial wealth, $x$ the investment amount, $y$ the value of the top prize, $\mathrm{z}$ the value of the bottom prize, $\mathrm{p}(\mathrm{x})$ the probability of winning the top prize where $\mathrm{p}^{\prime}(\mathrm{x})>0$, and $\mathrm{v}(\mathrm{w})$ the utility function where $v^{\prime}(w)>0$. The experimental task in person i's initial choice in the baseline situation is

$$
\operatorname{Max}_{x_{i}} p\left(x_{i}\right) v\left(w+y-x_{i}\right)+\left(1-p\left(x_{i}\right)\right) v\left(w+z-x_{i}\right) .
$$

We denote the optimal $\mathrm{x}_{\mathrm{i}}$ chosen during the RTI part by person $\mathrm{i}$ at time $\mathrm{t}$ by $\mathrm{x}_{\mathrm{i}}{ }^{*}$.

In the real-time information case, all participants can observe the entire vector of $X_{t}$ of responses at any point $\mathrm{t}$, where $\mathrm{t}$ is from 0 to 2 minutes. In the RTI environments, the value of $\mathrm{x}_{\text {ir }}$ will be the optimal choice conditional on observing this information, or

$$
\mathrm{X}_{\mathrm{ir}}=\left(\mathrm{X}_{\mathrm{i}}^{*} \mid \mathrm{X}_{\mathrm{t}}\right)
$$

Because the $\mathrm{p}(\mathrm{x})$ function is shared information for all participants, observing $\mathrm{X}_{\mathrm{t}}$ does not provide information about $\mathrm{p}(\mathrm{x})$ as in the standard models of herding and information cascades.

\footnotetext{
${ }^{10}$ Results in Blinder and Morgan (2005) indicate that the speed of decision making is similar for majority rule and unanimity.
} 
Observing $X_{t}$ may provide information about whether the individual has made the correct lottery decision. ${ }^{11}$ Consider a simple case in which the person initially chose $\mathrm{x}_{\mathrm{i} 0}$ but thought that there was a nonzero probability that $\mathrm{x}_{\mathrm{i} 0}-\varepsilon$ or $\mathrm{x}_{\mathrm{i} 0}+\varepsilon$ was the expected utility-maximizing choice, so that there could be errors in either direction. The error could arise because the individual may have difficulty performing the expected utility calculation for the lottery or may be uncertain about the underlying utility function that should guide decisions. If many group members pick $\mathrm{x}_{\mathrm{i}}$ values above $\mathrm{x}_{\mathrm{i} 0}$, the individual may increase the assessed likelihood that a higher investment choice is optimal even though there is no group aspect to the decision other than information regarding their decisions. Similarly, observing that others are disproportionately choosing lower investment levels may lead the individual to lower the chosen investment amount.

For the majority decision rule, an individual chooses an optimal $\mathrm{x}_{\mathrm{im}}$ and under the unanimity decision rule an individual chooses an optimal $\mathrm{x}_{\mathrm{iu}}$, given both the information about $\mathrm{X}_{\mathrm{t}}$ and knowledge of the group decision rule $\mathrm{m}$ or $\mathrm{u}$, which affects the salience of the components of $X_{t}$. The experimental instructions specify that for majority rule the fourth-highest payoff will determine the decision affecting all members in the group, while for the unanimous choice rule it is the lowest, or sixth-highest investment amount in the group of six that determines the shared group's investment. If the i values are used to denote the ordinal rank in the group decision context, the investment value is $\mathrm{x}_{4 \mathrm{~m}}$ for majority rule and $\mathrm{x}_{6 \mathrm{u}}$ for unanimity.

We examine our first hypothesis of risky shifts in investment amounts by comparing the values of $\mathrm{x}_{\mathrm{i} 0}$ and $\mathrm{x}_{\mathrm{ir}}$, which are affected only by the information $\mathrm{X}_{\mathrm{t}}$ and not by the framing effect of a group decision rule. While it may, for example, be the case that $\mathrm{x}_{\mathrm{im}}>\mathrm{x}_{\mathrm{i} 0}$ and $\mathrm{x}_{\mathrm{iu}}>\mathrm{x}_{\mathrm{i} 0}$, the

\footnotetext{
${ }^{11}$ There is an emerging literature on noise exhibited using different elicitation procedures, such as the recent contributions by Anderson and Mellor (2009) and by Hey, Morone, and Schmidt (2009). Noise could arise due to the elicitation procedure or because of unstable preferences. For our situation, we hypothesize that one potential source of noise is error in making complicated decisions involving lotteries.
} 
group decision rule's framing effects also may affect the observed shifts. For the range of choices selected by the respondents, increasing the investment in the group context raises the expected value of the lottery, and we examine both the direction of the shift and whether the investment level is beyond the point where the expected payoff is at its maximum value.

Hypothesis 1. Providing real-time information about others' choices will produce a risky shift.

Based on the initial distribution of investment values, $\mathrm{x}_{40}>\mathrm{x}_{60}$ by definition. Unless the framing effect of the decision rule alters this ranking in an unexpected manner, the fourth-highest investment amount with majority rule will exceed the lowest investment amount with unanimity. There is no unambiguous theoretical prediction for the relation of the average investment in the observe environment $\overline{\mathrm{x}}_{\text {ir }}$ and $\mathrm{x}_{40}$ and $\mathrm{x}_{60}$, as that will depend on how the framing effect of the group decision rule alters the subsequent distribution of responses. We expect the majority rule and the unanimous rule to influence the group decision differently.

Hypothesis 2. The group investment choice with majority rule $x_{4 m}$ should exceed the group choice with unanimity $x_{6 u}$.

For the RTI group treatments we expect the following trends in investment behavior.

Hypothesis 3. Each of the three group environments will generate changes in levels of investment. 3a) For the RTI observe treatment, there should be an increase in $x_{i r}$ levels above the $x_{i 0}$ values if there is a risky shift. There is no framing effect that will influence the 
distribution of these changes. 3b) For majority rule with RTI, there may be a risky shift, but there should also be a convergence toward the median with decreases in high values and increases in low values. 3c) For unanimous choice with RTI, there may also be a risky shift, but the low values may rise relative to the higher values, and there may be downward movement from the higher values because of the role of social norms and the asymmetry of the decision rule.

We test these hypotheses in two ways. First, we examine the direction of movement. Do more people increase their $\mathrm{x}_{\mathrm{i}}$ values or decrease them, and on balance is the magnitude of the increases greater? Second, we explore the within-group composition of the movement. Thus, do the particular ranks within the $\mathrm{X}_{\mathrm{t}}$ group change their $\mathrm{x}_{\mathrm{i}}$ values in the predicted manner?

The experiments were run both in the normal order in which individuals made their own investment decisions and reversed order in which the group context was first and the individual choice followed. If the provision of RTI provides information about the optimal risky investment choice that subjects take into account when valuing the lottery decisions, then for the reversed order there should be a lasting effect of RTI that also influences the subsequent individual choice. Thus, there should not be a reversal of the effect of the RTI group information if there is actual learning and information acquisition associated with the RTI.

Hypothesis 4. There should not be a reversal of the effects of RTI in the reversed order experiment if RTI has a lasting effect on the perception and valuation of lotteries. 
Our fifth hypothesis examines the relation between the person-specific measures of the constant relative risk aversion (CRRA) obtained using the Holt-Laury procedure and the group investment decision. More risk-averse respondents should make lower investment levels. The effect of respondent gender, which may be correlated with risk attitudes, will also be examined.

Hypothesis 5. Higher levels of individual risk aversion will tend to decrease the size of any risky investment.

\section{Summary of Individual and Group Investment Decisions}

Table 3 highlights data from Parts III and IV of the experiments with the choices in Table 2. Column (1) lists each group of six subjects by treatment. There are four groups in each treatment. In each treatment $n=24$. There are three treatments that have individual choices before subjects are placed in a group choice environment, denoted by original order with a total $\mathrm{n}=72$. As already described, Part III and Part IV of the experiment may be switched. These are the reversed order treatments. There are three treatments that have individual choices after the group exposure, denoted by reversed order with a total $n=72$.

Columns numbered 2-4 display the investment amounts. Column (2), labeled "Average Individual Investment," is the amount that each person in the group of six would pay to go forward with the litigation. The Group Environment column, column (3), is the average that a group of six players would invest. This is Part IV of the experiment in its original order and may precede Part III in the reversed order treatment. This is not the actual amount paid when the decision was made by the majority or a unanimous rule. For the Original-Majority and 
Reversed-Majority groups the amount paid was decided by the fourth-highest amount. The amount that each person actually settled upon in the group environment is shown on the right side of Table 3 in column (4). For example, the average that group Original-Majority-1 wanted to pay was $\$ 1.46$, and the amount paid based on the group decision rule was $\$ 1.25$. The amounts listed from lowest to highest $1.25,1.25,1.25,1.50,1.50,2.00$ are what each person settled upon as their vote to pay, knowing that there was a majority rule enforced.

There are 72 subjects who make an individual choice in stage 3 before group interaction and 72 subjects who make the same choice in stage 4 after group interaction. Table 3 allows us to make some preliminary observations on how much a group invests compared to what members would do individually. Comparing the investments subjects make in and out of a group setting, it is clear that the Observe treatment in the bottom two panels of Table 3 has the greatest impact on individual behavior.

Individuals alone in the Original-Observe and Reversed-Observe treatments make an average investment of $\$ 2.01$, but when they observe the decisions of others in the group, their investment rises to $\$ 2.62$. This is about a $30 \%$ difference so there is a substantial risk shift consistent with the risky shift predicted by Hypothesis 1. However, this investment level is not different from $\$ 2.50$ at $10 \%$ or less significance levels. Mandatory group action tempers the difference between what the individual would do alone and in a group setting. In the OriginalMajority and Reversed-Majority treatments, individuals alone would invest $\$ 2.40$, but with group input their average individual values rise to $\$ 2.45$. In the Original-Unanimous and Reversed-Unanimous treatments individuals alone would invest $\$ 2.20$, and with group input 
investments fall to $\$ 2.07$. Tests for significant differences in means are conducted by a simple difference of means test. ${ }^{12}$

The average individual investments in the Original-Observe and Reversed-Observe individual choice treatments are significantly different than the individual investments in the group setting at a critical level of $10 \%$ or less. Subjects invest significantly more when they are simply informed in an interactive process of what others are doing. In contrast, the average individual investments in the Original-Majority and Reversed-Majority treatments and the amounts actually paid in the group environment are not significantly different. As well, the average individual investments and those voted by the group in the Original-Unanimous and Reversed-Unanimous treatments are not significantly different.

Hence a group decision governed by either a majority or unanimous rule will not yield a group average that is significantly different than what the average individual would recommend for litigation. A majority rule will not yield an investment decision that is significantly different from what the average individual in the group would recommend. The investment will be significantly lower with unanimous rule, as predicted by Hypothesis 2 . Table 3 shows that the Original-Unanimous and Reversed-Unanimous groups respectively pay $22 \%$ and $34 \%$ less than the average individual in the group. Hence while majority rule represents the average individual in the group, unanimous rule is substantially more conservative in amounts spent.

This is not the case when the people make an individual decision to move forward when they simply observe what other individuals are doing. The Original-Observe treatments in the experiment yield significantly higher investment amounts than when the investment amount is

\footnotetext{
${ }^{12}$ The sample variance of the difference is $s_{D}^{2}=s_{(x-y)}^{2}=s_{x}^{2}+s_{y}^{2}-2 s_{x y} . \quad s_{\bar{D}}^{2}=s_{D}^{2} / n . \bar{D}=\bar{X}-\bar{Y}$. The test statistic is $\bar{D} / s_{\bar{D}}$. Number of observations is 24 unless otherwise noted. A normal table is used to decide significance.
} 
kept confidential. In the Original-Observe treatment subjects pay $45 \%$ more to go forward with a case in the informed setting as opposed to the confidential setting. In the Reversed-Observe setting they pay $19 \%$ more. We note that subjects in both the Original-Observe and ReversedObserve group environments are inclined to invest more than the $\$ 2.50$ amount that maximizes expected value. However, the respective $\$ 2.63$ and $\$ 2.61$ average investments are not significantly different from $\$ 2.50$.

\section{Analyses of Individual Choices in the Group Decision Contexts}

We now turn to a more careful comparison of the results in the different group decision contexts. Aggregated observations can cancel out differences in individual behavior patterns. Table 3 for example indicates that there are effects on the mean riskiness of decisions, but focusing on the means and abstracting from the composition of individual choices may give an inaccurate characterization of risk shifts. Participants in the group contexts all shared the same information about decisions by others and could use this information either in making a decision affecting their payoffs alone or as part of the majority or unanimous rule group decision process. How the information is used, however, may be conditional on outcomes in other stages of the experiment and other factors such as risk aversion and gender. We present the analysis beginning with the original order results so that we can analyze the individual decision, and the subsequent effect on individual decisions of decision making within the group and RTI environments. We then consider the reversed order treatments to examine the permanency of the effect of the information presented in the group contexts.

\subsection{OLS Regression Results}


The regression results in Table 4 analyze the determinants of the person's individual investment amount in the Part IV group decision context for original order. All group contexts include RTI, and the dependent variable is the person's individual investment level decision in Part IV of the experiment, not the total group investment level. The individual investment decisions variables in Table 4 all pertain to individual experiments in which there is no group component so that there is no interdependency of these variables across respondents. The first model includes the value of the individual investment in the Part III individual decision as well as indicators for Original-Majority and Original-Observe individual choice. The omitted category is that of group decisions when unanimity is required for decisions, OriginalUnanimous. The second and third equations include four additional demographic variables - the measure $r$ of the person's CRRA, the number of safe choices made in Table A.1, an indicator variable for whether the respondent is female, and an indicator variable for people who gave inconsistent answers to the choices in Table A.1. ${ }^{13}$

The results indicate a consistent significant influence of Original-Observe. Consider first the results for model 1 in Table 4. Individual investments in group situations are not significantly increased by higher levels of individual investments in the earlier stage. Investments in the group context are higher for the Original-Observe treatments than for the omitted category of unanimous choice, consistent with the risky shift predicted by Hypothesis 1 . The effect for majority rule is positive, not as great as Original-Observe, and not statistically significant at the usual levels. However, that treatment involves both RTI and framing effects that may affect any risky shift influence of RTI.

\footnotetext{
${ }^{13}$ Estimates for the subsample of 118 consistent respondents are very similar as one might expect given the lack of statistical significance for the variable pertaining to inconsistent responses.
} 
Models 2 and 3 in Table 4 add demographic variables to the analysis. The earlier effects remain the same. Female participants, who some studies suggest may be more risk-averse, ${ }^{14}$ make larger investments in the group context, but this difference is not statistically significant. There is no statistically significant effect of the measure of CRRA in model 2 and the alternative measure of risk aversion, the number of safe choices, which is included in model 3, so that there is no evidence in support of the risk aversion predicted by Hypothesis $5 .^{15}$

Since previous studies on probabilistic decisions have found that success or failure in a previous decision has an impact on future decisions (even when the probabilities themselves did not change), we add the interaction of the individual investment with an indicator for whether the person won the lottery in Part III in model 4, but this variable is also not statistically significant. The only significant effect for the average group investment results in Table 4 is OriginalObserve. Simply observing the investment behavior of other subjects, while continuing to ask each person for a personal decision on how much to spend, causes subjects to increase their investment by about $\$ 0.70$ in the first three models. This result is consistent with the raw data reported in Table 3. Before observing others, subjects were investing $\$ 1.82$ in the endeavor. The $\$ 0.70$ increase after observing others is about a $38 \%$ increase.

To examine whether the RTI effects have a lasting impact on subjects' decisions, Table 5 reports the counterparts of the Table 4 models for the reversed order sample. The dependent variable is the individual's investment in a final individual decision stage, while the explanatory variables include variables from the prior group decision stage. One difference from model 4 is that there is an indicator variable for whether the person's group had a successful lottery

\footnotetext{
${ }^{14}$ We did not detect any gender effect on the lottery choices in Part I. For a review of experimental studies of gender differences in risk aversion, see Eckel and Grossman (2008b).

${ }^{15}$ Some of the effect of risk aversion may be captured already in the individual expenditure variable. Omission of that variable from the various regressions sometimes boosts the statistical significance of the CRRA variable, leading to $t$ statistics above 1.0 but falling short of the usual test levels for statistical significance.
} 
outcome in the initial group decision. ${ }^{16}$ Moreover, for the reversed order regressions in Table 5, the individual expenditure variables are not independent of one another, as they were chosen within a group information context. To account for this relationship, all reported standard errors for Table 5 are clustered based on the subject's group. These are the only regression results in which there is this group interdependence among the explanatory variables. The absence of a statistically significant effect of the Reversed-Observe variable in the individual investment round indicates that the original order effect of Original-Observe is not reversed when people receive the group information in the initial round. There is a lasting informational effect of RTI, consistent with Hypothesis 4. This result is also reflected in the positive effect of the level of individual investment in the prior group situation on subsequent individual choices. Whereas individual investments did not affect investments in a group in Table 4, the investment made after observing others in the group does affect individual investments. It is interesting that after leaving the group context, female respondents exhibit a downward risk shift so that the results indicate more risk taking behavior by females in the group context than the individual context. ${ }^{17}$

The decision patterns giving rise to these effects are shown in Table 6, which presents the fraction of respondents for each treatment who have a greater investment amount, the same investment amount, or a lower investment amount in the different group RTI situations compared to the individual choice without RTI. Majority rule, in which the median person is most

\footnotetext{
${ }^{16}$ Including the measure of whether the person won in the earlier group lottery captures the outcome which, unlike the normal order case, depends on the group decision and not necessarily on the individual decision.

${ }^{17}$ There is mixed evidence over whether males and females exhibit different levels of risk aversion; see for example Schubert et al. (1999). Charness and Gneezy (2007) present evidence showing that when it comes to making investment decisions, women are more risk-averse than men. Gneezy, Niederle, and Rustichini (2003) and Niederle and Vesterlund (2007) raise the argument "that males and females preferences are affected differently by changes in the institution..." (Gneezy et al. 2003, p.1052). The competitiveness of the decision environment, in particular, causes men and women to behave differently. It is possible in this treatment that after observing the choices of others, females gained the confidence to take more risk, an interpretation consistent with results in Healy and Pate (forthcoming), who find that a "gender competition gap" is decreased in team settings.
} 
influential, is the neutral context as about an even number of people raise or lower their investments in the group situation. For the original order results, more people raise their values in the majority rule situation, while for the reversed order results the distribution of changes is more even. Overall, $90 \%$ of the people in the majority rule groups change their values from when the decision was personal, even though there is no reason to change if others' choices have no information value.

In contrast, if unanimous choice governs the group decision, the focal point becomes the lower bound of the individual investments. Once again there is no conventional economic rationale for people to alter their investment as they should continue to express their own preferences. Yet almost twice as many people reduce their investment amount as compared to the number who raise the amount; $75 \%$ of the subjects in unanimous rule choose lower or the same amounts voted individually. For the unanimous choice original order case, almost twice as many people reduce their investment as compared to the number that raise the investment, and there is also a much greater tendency to not change one's decision compared to the frequency of change under majority rule.

The strongest differential effect is that for the Observe treatment. For the original order case, three-fourths of the respondents raise their investments, and only one-fifth lower their investments. For the full sample, 58\% raise their investment level when they can observe what others do. On balance, observing others' choices makes people willing to incur a greater investment in the litigation. This pattern reflects the strong herding effects in Hypothesis 1 and 3a, which are not offset by any framing effects that would arise if there were a group decision rule. Knowledge of the greater investments by others may make people more willing to engage in similar behavior than they would otherwise be doing individually. Increasing investment 
amounts displays a risky shift that on average takes respondents, who are generally risk-averse, to an investment level slightly beyond expected value maximization.

\subsection{Ordered Probit Results}

The determinants of whether individual investments increase, stay the same, or decline when placed in a group situation can be explored through the ordered probit results in Table 7. Model 1 includes the individual investment amount, Original-Majority, and Original-Observe; model 2 adds the demographic variables. Higher individual investments in the initial round in Part III make it more likely that the respondent will reduce the investment rather than increase the investment in the group treatments in Part IV. The effect of the variable on the direction in which investment levels change in the group context is positive for both majority rule and the simple observing treatment, where these effects are relative to the unanimity treatment. RTI alone without majority rule has a greater positive effect than unanimity, but the difference of RTI compared to the majority rule case is not statistically significant. Neither the measure of risk aversion nor the variable for female respondents is statistically significant. Inconsistent respondents display a negative effect.

The results thus far do not pertain to how one's relative position within a group affects the influence of the group decision treatments. Original-Observe has no focal point and is purely informational. Original-Majority makes the median the focal point; and individuals tend to pull toward the median from both extremes due to the social norm role of the median. OriginalUnanimous makes the lower bound the focal point. The rule creates power for the lowest contributor. 
The ordered probit regressions in Table 8 address these within-group effects on the composition of the determinants of whether people increase, do not change, or decrease their individual investment in the group context. The focus of this analysis is somewhat different than in Table 7, in that we consider who within the group is altering their behavior. Here we create dummy variables for whether the person's individual investment in the individual choice case in Part III is in the top two investments or the bottom two investments in their group of six individuals. The omitted dummy variable category consists of the individuals who rank third and fourth in the level of their individual investments. Relative to this median group, how do individuals alter their investment amount in each of the three situations?

The regressions in Table 8 address this question after breaking up the sample into the three pertinent group decision subsamples — whether the respondent was in the Original-Observe group, the Original-Majority group, and the Original-Unanimous group. Within the OriginalObserve group, the bottom two investments rise after observing RTI. The provision of RTI creates a positive risky shift on the part of the participants with lowest rates of investment.

The existence of significant effects at the extremes for majority rule is consistent with the median focal point nature of majority rule. The top investment group decreases their investment, while those at the bottom raise their investment. This pattern indicates a convergence of the valuations toward the median within the majority rule treatment, where the change is exhibited at both extremes. This result is consistent with Hypothesis $3 \mathrm{~b}$.

For the unanimous choice rule, there is an asymmetric effect relative to the median, which is consistent with the unanimous choice rule's focus on only the extreme lower end of the investment distribution and with Hypothesis 3c. The bottom two individual investments, which will be instrumental in driving the group decision, rise relative to the median within this group as 
these individuals apparently attempt to accommodate the preferences of the group by raising their valuations in the group context. However, the extent of the upward movement is far less than for either Original-Majority or Original-Observe, which are significantly larger than the Original-Reversed effect at the $1 \%$ level. Thus, the additional unanimous choice component leads the subjects with the bottom investment levels to display less upward flexibility than either the RTI or majority rule case. Information alone without the unanimity group decision rule creates more upward movement on the part of the low end investors than in the unanimity group decision context, so the presence of the low bid framing effect for unanimity has a marginal effect that lowers rather than raises the bottom bid.

\section{Conclusion}

In a standard simple economic model of group decisions, individual preference structures carry over to the group context. ${ }^{18}$ Our work shows that group investment decisions are driven by individual preferences that are not the same as when people make individual choices in isolation. We believe the root cause of the shift is that people are undecided about the expected utilitymaximizing choice when risky investment decisions must be made at a personal level.

Information about others' choices has very strong effects. Even when people have full, accurate knowledge of the payoffs and the probabilities, observing others' choices creates a risky shift. Unlike models of herding and information cascades, in our experiments people have full knowledge of both the probabilities and the payoffs. Moreover, unlike other studies of risky shifts in group contexts, there is no personal interaction within the group, only exchanges of realtime information. Observing others' decisions with real-time information may enable people to

\footnotetext{
${ }^{18}$ Similarly, empirical simulations of group decisions generally are based on random draws of individual choices to construct a synthetic group. This approach has been used in several law and economics studies of jury behavior.
} 
make better decisions if their initial private choices are derived from noisy preferences in a complex decision environment where it is difficult to ascertain the expected utility-maximizing choice.

A second set of factors that alter individual choices stems from the group decision rule itself. How the decision rule is framed alters the individual choices people make even when their change in preferences will not alter the group decision in the majority rule and unanimity situations considered. The anchoring effect of focusing on the median group member for majority rule or the member with the lowest valuation for unanimity may influence social norms in a manner that alters individual choices when placed in a group context. The degree of accommodation of other group members' preferences is greater for majority rule than for unanimous choice. These effects may become even more pronounced when there is greater personal interaction that goes beyond observing others' decisions on a computer screen. ${ }^{19}$

Movement from individual decisions to a group decision context often creates many economic ramifications, including strategic behavior and related game-theoretic effects. However, even apart from such influences, there are quite fundamental changes in individual choice behavior in terms of the information affecting decisions, how people use the information available in group contexts to make decisions when preferences are noisy, and how the group decision rule frames decisions in a manner that alters subsequent behavior. These alterations can have lasting effects on an individual's subsequent decisions.

\footnotetext{
${ }^{19}$ Evidence in Charness, Rigotti, and Rustichini (2007) and, for non-strategic environments, Sutter (2009) suggests that increasing the salience of group membership enhances group effects.
} 


\section{References}

Ambrus, A., Greiner, B., \& Pathak, P. (2009). Group versus individual decision-making: Is there a shift? Institute for Advanced Study, School of Social Science Economics Working Paper 0091.

Anderson, L. R., \& Holt, C. A. (1997). Information cascades in the laboratory. American Economic Review, 87(5), 847-862.

Anderson, L. R., \& Mellor, J. M. (2009). Are risk preferences stable? Comparing an experimental measure with a validated survey-based measure. Journal of Risk and Uncertainty, 39(2), 137-160.

Aronson, E., Wilson, T. D., \& Akert, R. M. (2005). Social psychology. $5^{\text {th }}$ ed. Upper Saddle River, N.J.: Pearson.

Banerjee, A. V. (1992). A simple model of herd behavior. Quarterly Journal of Economics, 107(3), 797-817.

Bikhchandani, S., Hirshleifer, D., \& Welch, I. (1992). A theory of fads, fashion, custom, and cultural change as informational cascades. Journal of Political Economy, 100(5), 9921026.

Bikhchandani, S., Hirshleifer, D., \& Welch, I. (1998). Learning from the behavior of others: Conformity, fads, and informational cascades. Journal of Economic Perspectives, 12(3), 151-170.

Blinder, A. S., \& Morgan, J. (2005). Are two heads better than one? Monetary policy by committee. Journal of Money, Credit, and Banking, 37(5), 789-811.

Brown, R. (1986). Social psychology: The second edition. New York: Free Press. 
Charness, G., \& Gneezy, U. (2007). Strong evidence for gender differences in investment. SSRN Working Paper.

Charness, G., Rigotti, L., \& Rustichini, A. (2007). Individual behavior and group membership. American Economic Review, 97(4), 1340-1352.

Cooper, D. J., \& Kagel, J. H. (2005). Are two heads better than one? Team versus individual play in signaling games. American Economic Review, 95(3), 477-509.

Daughety, A. F., \& Reinganum, J. F. (1999). Stampede to judgment: Persuasive influence and herding behavior by courts. American Law and Economics Review, 1(1), 158-189.

Eckel, C. C., \& Grossman, P. J. (2008a). Forecasting risk attitudes: An experimental study using actual and forecast gamble choices. Journal of Economic Behavior and Organization, 68(1), 1-17.

Eckel, C. C., \& Grossman, P. J. (2008b). Men, women and risk aversion: Experimental results. Working paper. Forthcoming in C. Plott and V. Smith (eds.), Handbook of Experimental Results. New York: Elsevier.

Fischbacher, U. (2007). z-Tree: Zurich toolbox for ready-made economic experiments. Experimental Economics, 10, 171-178.

Fischhoff, B. (1983). Predicting frames. Journal of Experimental Psychology: Learning, Memory \& Cognition, 9, 113-116.

Glaeser, E. L., \& Sunstein, C. R. (2009). Extremism and social learning. Journal of Legal Analysis, 1(1), 263-324.

Gneezy, U., Niederle, M., \& Rustichini, A. (2003). Performance in competitive environments: Gender differences. Quarterly Journal of Economics, 118(3), 1049-1074. 
Goette, L., Huffman, D., \& Meier, S. (2006). The impact of group membership on cooperation and norm enforcement: Evidence using random assignment to real social groups. American Economic Review, 96(2), 212-216.

Guarnaschelli, S., McKelvey, R. D., \& Palfrey, T. R. (2000). An experimental study of jury decision rules. American Political Science Review, 94(2), 407-423.

Hargreaves-Heap, S., \& Zizzo, D. J. (2009). The value of groups. American Economic Review, 99(1), 295-323.

Healy, A., \& Pate, J. (2011). Can teams help to close the gender competition gap? Economic Journal, 121, DOI: 10.1111/j.1468-0297.2010.02409.x

Hey, J. D., Morone, A., \& Schmidt, U. (2009). Noise and bias in eliciting preferences. Journal of Risk and Uncertainty, 39(3), 213-235.

Holt, C. A., \& Laury, S. K. (2002). Risk aversion and incentive effects. American Economic Review, 92(5), 1644-1655.

Kerr, N. L., MacCoun, R. J., \& Kramer, G. P. (1996). Bias in judgment: Comparing individuals and groups. Psychological Review, 103(4), 687-719.

Lorenz, J., Rauhut, H., Schweitzer, F., \& Helbing, D. (2011). How social influence can undermine the wisdom of crowd effect. Proceedings of the National Academy of Sciences, 108(22), 9020-9025.

Lusk, J. L., \& Coble, K. H. (2005). Risk perceptions, risk preference, and acceptance of risky food. American Journal of Agricultural Economics, 87(2), 393-405.

Niederle, M., \& Vesterlund, L. (2007). Do women shy away from competition? Do men compete too much? Quarterly Journal of Economics, 122(3), 1067-1101. 
Rook, L. (2006). An economic psychological approach to herd behavior. Journal of Economic Issues, 40(1), 75-95.

Schkade, D., Sunstein, C. R., \& Kahneman, D. (2000). Deliberating about dollars: The severity shift. Columbia Law Review, 100(4), 1139-1175.

Schubert, R., Brown, M., Gysler, M., \& Brachinger, H. W. (1999). Financial decision-making: Are women really more risk-averse? American Economic Review Papers and Proceedings, 89(2), 381-385.

Shupp, R. S., \& Williams, A. W. (2008). Risk preference differentials of small groups and individuals. Economic Journal, 118, 258-283.

Sutter, M. (2007). Are teams prone to myopic loss aversion? An experimental study on individual versus team investment behavior. Economics Letters, 97, 128-132.

Sutter, M. (2009). Individual behavior and group membership: Comment. American Economic Review, 99(5), 2247-2257.

Tan, J. H. W., \& Bolle, F. (2007). Team competition and the public goods game. Economics Letters, 96(1), 133-139.

Wallach, M. A., Kogan, N., \& Bem, D. J. (1962). Group influence on individual risk taking. Journal of Abnormal and Social Psychology, 65(2), 75-86. 
Table 1

Experimental Treatments

\begin{tabular}{|c|c|c|c|c|}
\hline Treatment & Stage 1 & Stage 2 & Stage 3 & Stage 4 \\
\hline $\begin{array}{l}\text { Original Order, } \\
\text { Majority }\end{array}$ & $\begin{array}{l}\text { Risk Aversion } \\
\text { Elicitation }\end{array}$ & $\begin{array}{c}\text { Lottery } \\
\text { with Non-linear } \\
\text { Expected } \\
\text { Values }\end{array}$ & $\begin{array}{c}\text { Part III: } \\
\text { Individual } \\
\text { Investment }\end{array}$ & $\begin{array}{l}\text { Part IV: Group } \\
\text { Investment with } \\
\text { Majority Rule }\end{array}$ \\
\hline $\begin{array}{l}\text { Original Order, } \\
\text { Unanimity }\end{array}$ & $\begin{array}{l}\text { Risk Aversion } \\
\text { Elicitation }\end{array}$ & $\begin{array}{c}\text { Lottery } \\
\text { with Non-linear } \\
\text { Expected } \\
\text { Values }\end{array}$ & $\begin{array}{c}\text { Part III: } \\
\text { Individual } \\
\text { Investment }\end{array}$ & $\begin{array}{l}\text { Part IV: Group } \\
\text { Investment with } \\
\text { Unanimity Rule }\end{array}$ \\
\hline $\begin{array}{l}\text { Original Order, } \\
\text { Observe }\end{array}$ & $\begin{array}{l}\text { Risk Aversion } \\
\text { Elicitation }\end{array}$ & $\begin{array}{c}\text { Lottery } \\
\text { with Non-linear } \\
\text { Expected } \\
\text { Values }\end{array}$ & $\begin{array}{c}\text { Part III: } \\
\text { Individual } \\
\text { Investment }\end{array}$ & $\begin{array}{c}\text { Part IV: } \\
\text { Individual } \\
\text { Investment with } \\
\text { Observing } \\
\text { Others }\end{array}$ \\
\hline $\begin{array}{l}\text { Reversed Order, } \\
\text { Majority }\end{array}$ & $\begin{array}{l}\text { Risk Aversion } \\
\text { Elicitation }\end{array}$ & $\begin{array}{c}\text { Lottery } \\
\text { with Non-linear } \\
\text { Expected } \\
\text { Values }\end{array}$ & $\begin{array}{l}\text { Part IV: Group } \\
\text { Investment with } \\
\text { Majority Rule }\end{array}$ & $\begin{array}{c}\text { Part III: } \\
\text { Individual } \\
\text { Investment }\end{array}$ \\
\hline $\begin{array}{l}\text { Reversed Order, } \\
\text { Unanimity }\end{array}$ & $\begin{array}{l}\text { Risk Aversion } \\
\text { Elicitation }\end{array}$ & $\begin{array}{c}\text { Lottery } \\
\text { with Non-linear } \\
\text { Expected } \\
\text { Values }\end{array}$ & $\begin{array}{l}\text { Part IV: Group } \\
\text { Investment with } \\
\text { Unanimity Rule }\end{array}$ & $\begin{array}{c}\text { Part III: } \\
\text { Individual } \\
\text { Investment }\end{array}$ \\
\hline $\begin{array}{l}\text { Reversed Order, } \\
\text { Observe }\end{array}$ & $\begin{array}{l}\text { Risk Aversion } \\
\text { Elicitation }\end{array}$ & $\begin{array}{c}\text { Lottery } \\
\text { with Non-linear } \\
\text { Expected } \\
\text { Values }\end{array}$ & $\begin{array}{c}\text { Part IV: } \\
\text { Individual } \\
\text { Investment with } \\
\text { Observing } \\
\text { Others }\end{array}$ & $\begin{array}{c}\text { Part III: } \\
\text { Individual } \\
\text { Investment }\end{array}$ \\
\hline
\end{tabular}


Table 2

Lottery Structure for the Individual and Group Investment Experiments*

\begin{tabular}{|c|c|c|c|c|c|}
\hline$\underline{\text { Payment }}$ & $\frac{\text { Probability of }}{\underline{\text { Outcome A }}}$ & $\frac{\text { Net Amount }}{\underline{\text { Paid for }}} \frac{\underline{\text { Outcome A }}}{}$ & $\frac{\text { Probability of }}{\underline{\text { Outcome B }}}$ & $\frac{\frac{\text { Net Amount }}{\text { Paid for }}}{\underline{\text { Outcome B }}}$ & $\frac{\text { Expected }}{\underline{\text { Value of }}}$ \\
\hline$\square \$ 0$ & 0.0 & - & 1.0 & $\$ 5.00$ & $(\$ 5.00)$ \\
\hline$\square \$ 0.50$ & 0.1 & $\$ 14.00$ & 0.9 & $\$ 4.50$ & $(\$ 5.45)$ \\
\hline$\square \$ 1.00$ & 0.2 & $\$ 13.00$ & 0.8 & $\$ 4.00$ & $(\$ 5.80)$ \\
\hline$\square \$ 1.50$ & 0.3 & $\$ 12.00$ & 0.7 & $\$ 3.50$ & $(\$ 6.05)$ \\
\hline$\square \$ 2.00$ & 0.4 & $\$ 11.00$ & 0.6 & $\$ 3.00$ & $(\$ 6.20)$ \\
\hline$\square \$ 2.50$ & 0.5 & $\$ 10.00$ & 0.5 & $\$ 2.50$ & $(\$ 6.25)$ \\
\hline$\square \$ 3.00$ & 0.6 & $\$ 9.00$ & 0.4 & $\$ 2.00$ & $(\$ 6.20)$ \\
\hline$\square \$ 3.50$ & 0.7 & $\$ 8.00$ & 0.3 & $\$ 1.50$ & $(\$ 6.05)$ \\
\hline$\square \$ 4.00$ & 0.8 & $\$ 7.00$ & 0.2 & $\$ 1.00$ & $(\$ 5.80)$ \\
\hline$\square \$ 4.50$ & 0.9 & $\$ 6.00$ & 0.1 & $\$ 0.50$ & $(\$ 5.45)$ \\
\hline
\end{tabular}

* Subjects were provided with all information shown except for the numbers in the final column. The lotteries described in this table have two possible outcomes, outcome A and outcome B, for which the associated probabilities and payoffs are given in the columns in the table. 
Table 3

Individual and Group Investments ${ }^{\text {a }}$

(1)

\begin{tabular}{ccc} 
& $(2)$ & $(3)$ \\
& Average & \\
Individual & Group \\
Group & Investment & Environment \\
\hline
\end{tabular}

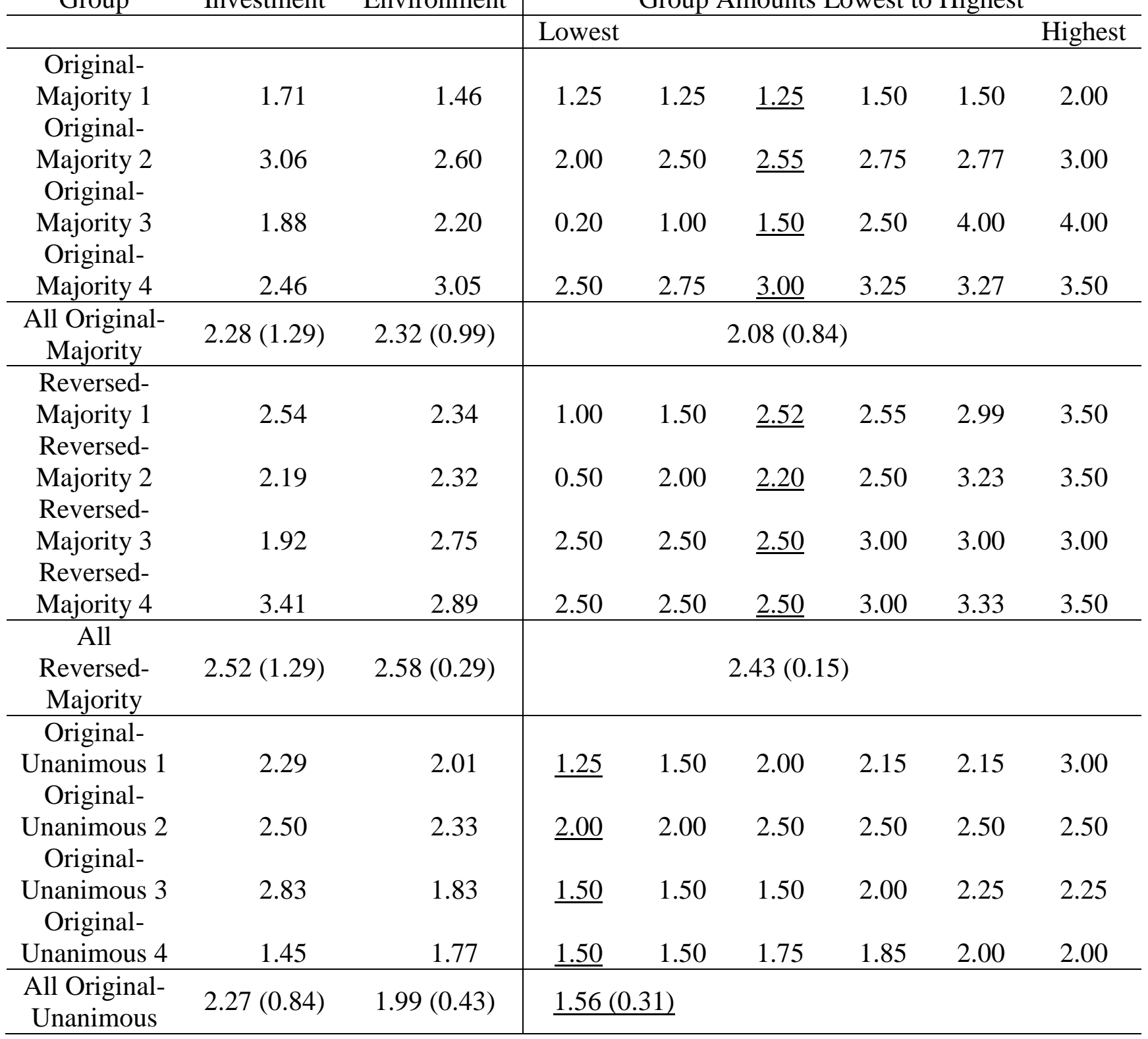

(4)

Group Amounts Lowest to Highest 
Table 3 cont'd.

(1) (2)

Average

Individual

Investment
(3)

3)

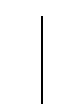

(4)

\begin{tabular}{ccc} 
& Average & \\
Individual & Group \\
Group & Investment & Environment \\
\hline
\end{tabular}

Group Amounts Lowest to Highest

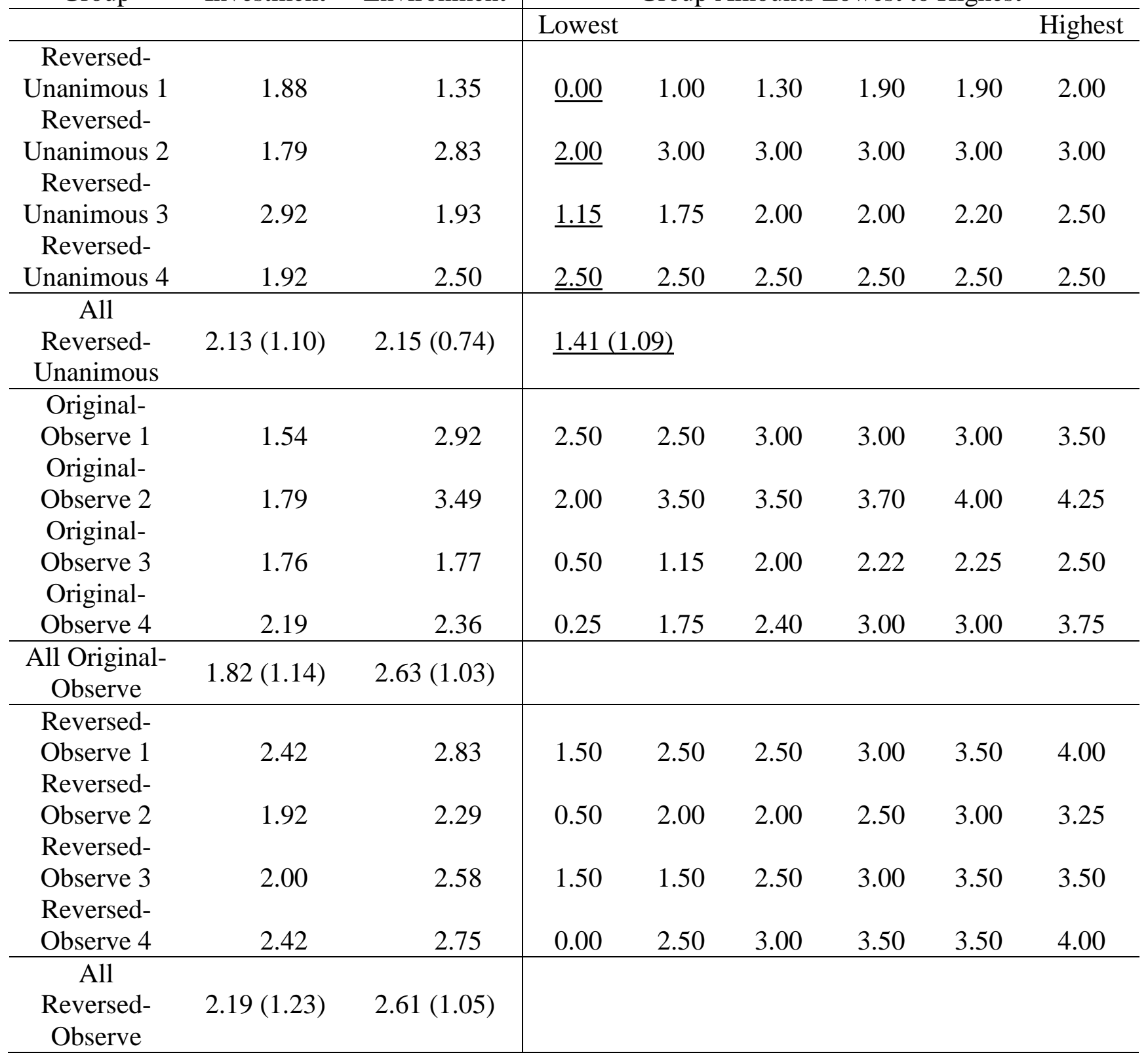

${ }^{a}$ Standard deviations of four observations are in parentheses. Underlined numbers reflect the investment amount dictated by the group decision rule. The bottom two panels for OriginalObserve and Reversed-Observe pertain to individual decisions without any group decision rule. 
Table 4

Regressions of Individual Investments in Group Decision Contexts, Original Order ${ }^{\text {a }}$ Independent Variable 1 $\underline{2}$ $\underline{3}$ $\underline{4}$

Individual investment

$$
\begin{gathered}
0.160 \\
(0.104) \\
- \\
0.338 \\
(0.218) \\
0.720 \\
(0.217)^{* *}
\end{gathered}
$$

0.145

$(0.101)$

0.145

0.306

Individual investment

$-$

(0.101)

(0.195)

$\times$ Win lottery

Original-Majority

0.317

(0.223)

0.317

0.701

$(0.233)^{* *}$

(0.223)

0.700

$-0.167$

CRRA

$-0.044$

(0.299)

Number of safe choices

$-$

$-$

Female

$-$

Inconsistent respondent

$-$

0.309

$(0.233) * *$

(0.129)

0.145

(0.214)

0.574

$(0.250) * *$

$-0.074$

(0.281)

Constant

1.622

$(0.242) * *$

$\mathrm{R}^{2}$

0.13

(0.206)

$-0.265$

$-0.012$

(0.086)

0.309

0.356

(0.206)

$-0.279$

(0.191)

$(0.453)$

(0.557)

$-0.280$

1.567

1.614

(0.433)

$(0.258)^{* * *}$

0.16

$(0.472)^{* *}$

0.16

1.547

$(0.263) * *$

0.19

${ }^{a}$ Statistics in parentheses are robust standard errors.

** Statistical significance at the 0.05 level, two-tailed test. 
Table 5

Regressions of Individual Investments in Individual Decision Contexts, Reversed Order ${ }^{\text {a }}$

\begin{tabular}{|c|c|c|c|c|}
\hline Independent Variable & $\underline{1}$ & $\underline{2}$ & $\underline{3}$ & $\underline{4}$ \\
\hline $\begin{array}{l}\text { Individual investment } \\
\text { in group context }\end{array}$ & $\begin{array}{l}0.468 \\
(0.157)^{* *} \\
{[0.165]^{* *}}\end{array}$ & $\begin{array}{l}0.494 \\
(0.175)^{* *} \\
{[0.202]^{* *}}\end{array}$ & $\begin{array}{l}0.493 \\
(0.174)^{* *} \\
{[0.200]^{* *}}\end{array}$ & $\begin{array}{l}0.526 \\
(0.170)^{* *} \\
{[0.206]^{* *}}\end{array}$ \\
\hline $\begin{array}{l}\text { Win lottery in group } \\
\text { context }\end{array}$ & - & - & - & $\begin{array}{l}-0.264 \\
(0.396) \\
{[0.284]}\end{array}$ \\
\hline Reversed-Majority & $\begin{array}{c}0.194 \\
(0.344) \\
{[0.442]}\end{array}$ & $\begin{array}{c}0.237 \\
(0.340) \\
{[0.439]}\end{array}$ & $\begin{array}{c}0.236 \\
(0.338) \\
{[0.439]}\end{array}$ & $\begin{array}{c}0.152 \\
(0.329) \\
{[0.447]}\end{array}$ \\
\hline Reversed-Observe & $\begin{array}{l}-0.154 \\
(0.330) \\
{[0.355]}\end{array}$ & $\begin{array}{l}-0.058 \\
(0.349) \\
{[0.299]}\end{array}$ & $\begin{array}{l}-0.058 \\
(0.349) \\
{[0.298]}\end{array}$ & $\begin{array}{l}-0.005 \\
(0.378) \\
{[0.245]}\end{array}$ \\
\hline CRRA & - & $\begin{array}{c}0.092 \\
(0.266) \\
{[0.270]}\end{array}$ & - & $\begin{array}{c}0.118 \\
(0.270) \\
{[0.264]}\end{array}$ \\
\hline Number of safe choices & - & - & $\begin{array}{c}0.029 \\
(0.079) \\
{[0.081]}\end{array}$ & - \\
\hline Female & - & $\begin{array}{l}-0.615 \\
(0.280)^{* *} \\
{[0.317]^{* *}}\end{array}$ & $\begin{array}{l}-0.613 \\
(0.279)^{* *} \\
{[0.317]^{* *}}\end{array}$ & $\begin{array}{l}-0.624 \\
(0.278)^{* *} \\
{[0.325]^{* *}}\end{array}$ \\
\hline Inconsistent respondent & - & $\begin{array}{c}0.200 \\
(0.543) \\
{[0.337]}\end{array}$ & $\begin{array}{c}0.258 \\
(0.639) \\
{[0.405]}\end{array}$ & $\begin{array}{c}0.248 \\
(0.554) \\
{[0.320]}\end{array}$ \\
\hline Constant & $\begin{array}{c}1.116 \\
(0.395)^{* *} \\
{[0.417]^{* *}} \\
0.13\end{array}$ & $\begin{array}{l}1.235 \\
(0.380)^{* *} \\
{[0.426]^{* *}} \\
0.19\end{array}$ & $\begin{array}{l}1.117 \\
(0.479)^{* *} \\
{[0.412]^{* *}} \\
0.19\end{array}$ & $\begin{array}{l}1.229 \\
(0.385)^{* *} \\
{[0.422]^{* *}} \\
0.20\end{array}$ \\
\hline
\end{tabular}

${ }^{a}$ Statistics in parentheses are robust standard errors. Statistics in brackets are robust and clustered standard errors.

** Statistical significance at the 0.05 level, two-tailed test. 
Table 6

Investment Decision Transitions ${ }^{\mathrm{a}}$

\section{Percent with Value in Group Decision RTI Context}

\begin{tabular}{lccc}
\hline & $\begin{array}{c}\text { Below Individual } \\
\text { Value }\end{array}$ & $\begin{array}{c}\text { Same as Individual } \\
\text { Value }\end{array}$ & $\begin{array}{c}\text { Above Individual } \\
\text { Value }\end{array}$ \\
\hline Full Sample & 42 & 10 & 48 \\
\hline Majority & 44 & 31 & 25 \\
Unanimous & 19 & 23 & 58 \\
Observe & & & 54 \\
\hline Original Order & 38 & 8 & 25 \\
Majority & 46 & 29 & 75 \\
Unanimous & 21 & 4 & 42 \\
Observe & & 13 & 25 \\
\hline Reversed Order & 46 & 33 & 42 \\
\hline Majority & 42 & 42 & \\
Unanimous & 17 & & \\
Observe & & & \\
\hline
\end{tabular}

${ }^{\text {a }}$ Each of the three full sample groups include 48 observations. Each of the two subsample groups include 24 observations. Numbers in row do not always add to 100 due to rounding. 
Table 7

Ordered Probit Regression for Whether Individual Investment in Group Context Is Higher or Lower than Individual Investment for Original Order ${ }^{\text {a }}$

Independent Variable

Individual investment

Original-Majority

Original-Observe

CRRA

Female

Inconsistent respondent

Pseudo $\mathrm{R}^{2}$

\section{1}

$-1.137$

$(0.300)^{* *}$

0.695

$(0.367)^{*}$

1.059

$(0.474)^{* *}$

$-$

$-$

$-$

0.31 $\underline{2}$

$-1.436$

$(0.287)^{* *}$

0.801

$(0.423)^{*}$

1.193

$(0.461) * *$

$-0.520$

$(0.605)$

0.043

(0.351)

$-2.001$

$(0.940)^{* *}$

0.36

${ }^{\text {a }}$ Statistics in parentheses are standard errors.

* Statistical significance at the 0.10 level, two-tailed test; ** statistical significance at the 0.05 level, two-tailed test. 
Table 8

Ordered Probit Regression for Effect of Relative Position on Whether Group Investment is Higher or Lower Relative to Median Respondents for Original Order ${ }^{\text {a }}$

\begin{tabular}{lllc}
\hline & $\begin{array}{l}\text { Original- } \\
\text { Observe }\end{array}$ & $\begin{array}{c}\text { Original- } \\
\text { Majority }\end{array}$ & $\begin{array}{c}\text { Original- } \\
\text { Unanimous }\end{array}$ \\
\hline Top two individual investments & -0.750 & -2.155 & -0.177 \\
& $(0.671)$ & $(0.660)^{* *}$ & $(0.824)$ \\
Bottom two individual investments & 7.359 & 9.004 & 1.243 \\
CRRA & $(0.633)^{* *}$ & $(1.162)^{* *}$ & $(0.755)^{*}$ \\
& -0.842 & 0.797 & -0.106 \\
Female & $(1.172)$ & $(1.004)$ & $(1.067)$ \\
Inconsistent respondent & -0.197 & 0.837 & -0.186 \\
& $(0.801)$ & $(0.618)$ & $(0.493)$ \\
Pseudo $\mathrm{R}^{2}$ & -17.830 & -0.224 & -0.087 \\
& $(1.880)^{* *}$ & $(1.649)$ & $(1.401)$ \\
\end{tabular}

${ }^{\text {a }}$ Statistics in parentheses are standard errors.

* Statistical significance at the 0.10 level, two-tailed test; ** statistical significance at the 0.05 level, two tailed test. 


\section{Appendix A: Measuring Risk Aversion}

To control for individual risk aversion, we obtained a measure of respondent risk aversion in stage 1 of the study. Individuals were asked to choose between two lottery options in ten different cases. The choices presented to subjects are in Table A.1.

The ten choices have two options labeled Option A and Option B. These options keep the same dollar and cents values as the choices change. The options are different over the ten choices because the probabilities in the choice change. Option A has progressively higher probabilities for winning $\$ 2.00$ and progressively lower probabilities for winning $\$ 1.60$. In Option B there are progressively higher probabilities of winning $\$ 3.85$ and progressively lower probabilities of winning $\$ 0.10$. The tenth decision is a choice between taking either $\$ 2.00$ or $\$ 3.85$ with certainty. The expected value of Option A in the first decision is $\$ 1.64$ and the expected value of Option B is $\$ 0.475$. Both expected values increase, but at a different rate: In choice five the expected value of Option B $(\$ 1.975)$ becomes larger than Option A $(\$ 1.80)$, and a risk-neutral subject should switch from Option A to Option B. Risk-loving subjects will switch sooner, and risk-averse subjects will switch later. Option A is considered a safe choice relative to Option B. One measure of risk aversion is the number of safe choices made before switching to Option B.

After all subjects have chosen either Option A or Option B in each of the ten scenarios, the computer randomly chooses one of the ten scenarios for investment and determines for each subjects whether they win or lose their chosen lottery. Before moving to Part II of the experiment subjects are informed of their earnings, and their screen begins to tabulate an earning balance. 
Based on their responses to Part I of the experiment and assuming a utility function of the form $\mathrm{v}(\mathrm{x})=\frac{\mathrm{x}^{1-\mathrm{r}}}{1-\mathrm{r}}$, where $\mathrm{r}$ is the measure of constant relative risk aversion (CRRA), Table A.2 provides the CRRA measure implied by the choice of Option B in the lottery and the fraction of respondents in each risk aversion group. There is a preference for risk if $r<0$, and there is risk aversion if $r>0$. Using the same intervals as Holt and Laury (2002) for measures of preference, subjects are risk-neutral if they have $r$ such that $-0.15<r<0.15$. Overall, $83 \%$ of the respondents are consistent in that they switch from Option A to Option B only once; of those, 17\% of the respondents display risk-loving preferences, $28 \%$ are risk-neutral, and 55\% are risk-averse. ${ }^{20}$ Only $3 \%$ of the sample with consistent choices fall into the extremely risk-loving group $(r<-0.95)$ or the extremely risk-averse group $(1.37<\mathrm{r})$. Most people display moderate degrees of risk aversion. For subsequent analysis we code as the individual's risk aversion measure the midpoint of the $r$ range or the level of the upper or lower bound on $r$ for people at the extremes. Nobody in the sample failed the rationality test in the final choice in Table A.1, and $17 \%$ of the sample switched decisions in Table A.1 more than once. Subsequent empirical analysis will distinguish the people without $r$ values and label them inconsistent respondents. The mean value of $r$ for those with valid measures of $r$ is 0.21 , which is a slight degree of risk aversion. On average consistent subjects made 4.82 safe lottery choices.

\footnotetext{
${ }^{20}$ Our subjects seem to be slightly less risk-averse than subjects in other papers who used the Holt-Laury mechanism: for example, in Holt and Laury (2002) itself, $8 \%$ were risk-loving, 26\% risk-neutral and 66\% riskaverse, while in Anderson and Mellor (2009) and Lusk and Coble (2005) those numbers were 5\%, 21\% and 75\%, and $12 \%, 24 \%$ and $64 \%$, respectively.
} 
Table A.1

Lotteries Used to Develop a Measure of Risk Aversion

1 Option A $\square 0.1$ probability of winning $\$ 2.00$ and 0.9 probability of winning $\$ 1.60$ Option B $\square 0.1$ probability of winning $\$ 3.85$ and 0.9 probability of winning $\$ 0.10$

2 Option A $\square 0.2$ probability of winning $\$ 2.00$ and 0.8 probability of winning $\$ 1.60$ Option B $\square 0.2$ probability of winning $\$ 3.85$ and 0.8 probability of winning $\$ 0.10$

3 Option A $\square 0.3$ probability of winning $\$ 2.00$ and 0.7 probability of winning $\$ 1.60$ Option B $\square 0.3$ probability of winning $\$ 3.85$ and 0.7 probability of winning $\$ 0.10$

4 Option A $\square 0.4$ probability of winning $\$ 2.00$ and 0.6 probability of winning $\$ 1.60$ Option B $\square 0.4$ probability of winning $\$ 3.85$ and 0.6 probability of winning $\$ 0.10$

5 Option A $\square 0.5$ probability of winning $\$ 2.00$ and 0.5 probability of winning $\$ 1.60$ Option B $\square 0.5$ probability of winning $\$ 3.85$ and 0.5 probability of winning $\$ 0.10$

6 Option A $\square 0.6$ probability of winning $\$ 2.00$ and 0.4 probability of winning $\$ 1.60$ Option B $\square 0.6$ probability of winning $\$ 3.85$ and 0.4 probability of winning $\$ 0.10$

7 Option A $\square 0.7$ probability of winning $\$ 2.00$ and 0.3 probability of winning $\$ 1.60$ Option B $\square 0.7$ probability of winning $\$ 3.85$ and 0.3 probability of winning $\$ 0.10$

8 Option A $\square 0.8$ probability of winning $\$ 2.00$ and 0.2 probability of winning $\$ 1.60$ Option B $\square 0.8$ probability of winning $\$ 3.85$ and 0.2 probability of winning $\$ 0.10$

9 Option A $\square 0.9$ probability of winning $\$ 2.00$ and 0.1 probability of winning $\$ 1.60$ Option B $\square 0.9$ probability of winning $\$ 3.85$ and 0.1 probability of winning $\$ 0.10$

10 Option A $\square$ winning $\$ 2.00$ with certainty Option B $\square$ winning $\$ 3.85$ with certainty 
Table A.2

Measures of Risk Aversion for the Sample

\begin{tabular}{ccc}
\hline & CRRA $(\mathrm{r})$ Implied by & \\
Number of safe choices & Option B & Fraction in group \\
\hline $0-1$ & $\mathrm{r}<-0.95$ & 0.017 \\
2 & $-0.95<\mathrm{r}<-0.49$ & 0.025 \\
3 & $-0.49<\mathrm{r}<-0.15$ & 0.125 \\
4 & $-0.15<\mathrm{r}<0.15$ & 0.283 \\
5 & $0.15<\mathrm{r}<0.41$ & 0.217 \\
6 & $0.41<\mathrm{r}<0.68$ & 0.225 \\
7 & $0.68<\mathrm{r}<0.97$ & 0.075 \\
8 & $0.97<\mathrm{r}<1.37$ & 0.017 \\
9 & $1.37<\mathrm{r}$ & 0.017 \\
10 & Failed rationality test & 0.000 \\
& & \\
\hline
\end{tabular}

The mean (std. deviation) of the number of safe choices is 4.82 (1.48), and the mean (std. deviation) of CRRA for those with valid r: $0.21(0.43)$. 


\section{Appendix B: Lotteries with Rising then Falling Expected Values}

To introduce participants to the type of lottery structure used in the main part of the experiment, Part II presents subjects with lottery choice scenarios that have a more complex expected payoff pattern; expected payoffs rise and then fall. Table B.1 has nine choices and choosing between options was designed to familiarize the subjects with more complex payoff patterns outside of contextual cues. As shown in Table B.1, Option A is winning $\$ 2.50$ with certainty, but Option B has both the probabilities and investments changing. Once again, after all subjects make their choices, the computer randomly picks one of the nine cases to pay. If subjects pick Option A in that case, $\$ 2.50$ is paid. If they pick Option B, the computer again decides randomly whether they win the lottery in Option B. The expected value of Option B is shown in parentheses; these values were not given to subjects in the experiment.

Notice the expected values of Option B are always greater than $\$ 2.50$. A risk-neutral or risk-loving subject would always choose Option B over Option A. A very risk-averse person with an $r$ value of greater than 1.14 will choose Option A from lottery 1 and never switch to Option B. Table B.1 is something of a sterile version of the litigation decision that is presented to subjects in Parts III and IV of the experiment, for which the expected values of the lotteries are double the values in Table B.1.

Table B.2 displays the basic information on when subjects switch from the safe Option A to the lottery in Option B and back. Of all 144 subjects, 127 switch at least once, with an average first lottery switch of 2.18 (std. dev. 1.95) and average last switch (back to Option A) of 7.88 (std. dev. 1.82). The number of times individual subjects switch between Option A and B also are reported. It is not unusual for subjects to make as many as four switches between options. The largest number of switches in the raw data is six. Counts of how individuals are actually 
switching show that people have difficulty with these lottery choices, which are more challenging than those in the main experiment. Just 56 or $39 \%$ of the subjects switch zero or two times; 60 (42\%) subjects only switch once, and 28 (19\%) switch more than twice.

Complications arise with respect to deciding when to enter and exit the lottery. The survey results from Table B.2 present compelling evidence that individuals are uncertain about whether they have made their expected utility-maximizing choices. We believe this uncertainty about their expected utility-maximizing choice allows people to be guided by RTI in a group environment, a theme to which we return when we discuss the experimental results.

The instructions for Table 2 are less demanding of subjects than those for Table B.1. In Part II of the experiment, subjects who do not show an extreme risk loving measure are required to enter and then exit the lottery in order to maximize expected utility. Table 2 facilitates the subjects' task by simply asking them at what point they would like to be in the "litigation lottery" and not when they would like to enter and continue with this lottery as relative payoffs change. 
Table B.1

Lotteries with Rising then Falling Expected Values

1 Option A $\square$ winning $\$ 2.50$ with certainty

Option B $\square 0.1$ probability of winning $\$ 7.00$ and 0.9 probability of winning $\$ 2.25$ ( $\$ 2.725$ )

2 Option A $\square$ winning $\$ 2.50$ with certainty

Option B $\square 0.2$ probability of winning $\$ 6.50$ and 0.8 probability of winning $\$ 2.00$ ( $\$ 2.90)$

3 Option A $\square$ winning $\$ 2.50$ with certainty

Option B $\square 0.3$ probability of winning $\$ 6.00$ and 0.7 probability of winning $\$ 1.75$ (\$3.025)

4 Option A $\square$ winning $\$ 2.50$ with certainty

Option B $\square 0.4$ probability of winning $\$ 5.50$ and 0.6 probability of winning $\$ 1.50(\$ 3.10)$

5 Option A $\square$ winning $\$ 2.50$ with certainty

Option B $\square 0.5$ probability of winning $\$ 5.00$ and 0.5 probability of winning $\$ 1.25$ (\$3.125)

6 Option A $\square$ winning $\$ 2.50$ with certainty

Option B $\square 0.6$ probability of winning $\$ 4.50$ and 0.4 probability of winning $\$ 1.00(\$ 3.10)$

7 Option A $\square$ winning $\$ 2.50$ with certainty

Option B $\square 0.7$ probability of winning $\$ 4.00$ and 0.3 probability of winning $\$ 0.75(\$ 3.025)$

8 Option A $\square$ winning $\$ 2.50$ with certainty

Option B $\square 0.8$ probability of winning $\$ 3.50$ and 0.2 probability of winning $\$ 0.50$ ( $\$ 2.90)$

9 Option A $\square$ winning $\$ 2.50$ with certainty

Option B $\square 0.9$ probability of winning $\$ 3.00$ and 0.1 probability of winning $\$ 0.25(\$ 2.725)$ 
Table B.2

Switching in Lotteries of Part II, Table B.1

\begin{tabular}{lc}
\hline $\begin{array}{l}\text { Average Stage of } \\
\text { First Switch: }\end{array}$ & $2.18(1.95)$ \\
\hline $\begin{array}{l}\text { Average Stage of } \\
\text { Last Switch: }\end{array}$ & $7.88(1.82)$ \\
\hline $\begin{array}{l}\text { Number with 0 } \\
\text { Switches: }\end{array}$ & 17 \\
\hline $\begin{array}{l}\text { Number with 1 } \\
\text { Switch: }\end{array}$ & 60 \\
\hline $\begin{array}{l}\text { Number with 2 } \\
\text { Switches: }\end{array}$ & 39 \\
\hline $\begin{array}{l}\text { Number with 3 or } \\
\text { more Switches: }\end{array}$ & 28 \\
\hline
\end{tabular}

$\mathrm{N}=144$, Standard deviations in parentheses. 